\title{
MUDANÇAS DE FINAL DE SÉCULO NO PADRÃO DE DISTRIBUIÇÃO DAS ATIVIDADES ECONÔMICAS NO ESTADO DE SÃO PAULO:
}

\section{O CASO DO “ABCD PAULISTA”}

\author{
JOSÉ MANUEL RODRIGUES LÚCIO \\ Universidade Nova de Lisboa
}

\section{A Economia Regional e os "Distritos Industriais"}

O conceito de "Distrito Industrial" radica na tradição marshalliana de "Atmosfera empresarial" de uma região, favorável à competitividade de um determinado território. $\mathrm{O}$ distrito industrial pode definir-se como uma "entidade socioterritorial caracterizada pela presença ativa de uma comunidade de pessoas e de uma população de empresas num determinado espaço geográfico e histórico" (BECATTINI, 1994: 20).

Os seus componentes principais englobam, deste modo:

uma comunidade local em que a característica mais marcante é um sistema de valores e de pensamento relativamente homogêneo e um corpo de instituições e de regras destinado a propagar os valores a todo o distrito;

uma população de empresas em que cada unidade tende a especializar-se numa única, ou em apenas em algumas, das fases dos processos produtivos de cada distrito; 
um conjunto de recursos humanos, onde cada indivíduo tende a procurar permanentemente o tipo de atividade profissional que melhor corresponde às suas aspirações elou atividades (cf. BECATTINI, 1994: 20-22).

A importância conferida ao estudo dos recursos humanos, da inserção geográfica (territorial) das empresas e a análise do papel das instituições permitem a apreensão de que a problemática do distrito industrial insere-se, portanto, numa questão mais global, envolvendo o "modo de funcionamento de um sistema produtivo". Em aberto, e precisando de novas análises complementares permanecem questões relativas a:

relações profissionais no seio das unidades de produção, a divisão do trabalho e das competências, bem como o tipo e o funcionamento dos mercados de trabalho locais;

diferentes modelos de governança externos às empresas, aqui incluindo instituições regionais ou nacionais;

aspectos qualitativos das relações interempresas, susceptiveis de relevar de tradições culturais (cf. STORPER e HARRISON, 1994: 186).

No contexto da problemática das economias regionais merece, também, particular realce o problema do papel destinado às cidades, uma vez que:

a aglomeração urbana pode ser considerada como um mecanismo de base que reúne uma vasta quantidade de capital e de trabalho no contexto da paisagem econômica. Assim, pode-se afirmar que sempre que se verificam transformações ao nível dos regimes de produção e das formas da atividade econômica, sucedem-se alterações correlativas nos modelos de urbanização e de desenvolvimento regional (SCOTT, 1994: 72).

Face ao que antecede, conclui-se que a evolução das análises de economia regional versando, por exemplo, a área específica dos distritos industriais, será indissociável da perspectivação dos problemas relativos não apenas à economia de produção urbana, como também "às questões de reprodução social, de vida cultural e de política de "cidade"” (SCOTT, 1994: 73).

Mais recentemente os estudos de Economia Regional têm procurado novas temáticas como sejam os "Meios Inovadores"1 - aos quais voltaremos um pouco mais à frente - as "Regiões Inteligentes" e os "Sistemas Regionais de Inovação". Em todos os casos pode-se concluir que:

${ }^{1}$ Neste sentido ver DICKEN, 1998: 172-174. 
os contributos da Economia Territorial de Inovação, vieram, assim, enriquecer as leituras das dinâmicas de desenvolvimento regional. A existência de competências específicas, a capacidade de cooperação entre os actores, a solidariedade institucional, os processos coletivos de aprendizagem e o fomento do potencial de inovação constituem, afinal, ingredientes fundamentais do desenvolvimento empresarial e territorial. (SANTOS, 2002b: 313)

A promoção do desenvolvimento à escala regional e, sobretudo, local depende, em larga margem, das capacidades (recursos) existentes em capital humano. Consideramos, no âmbito da presente análise, capital humano como "os conhecimentos, as idéias, o saber-fazer, que estão encarnados nas populações" (POLÈSE, 1998: 157). Deste modo, o sucesso de uma política de desenvolvimento local estará correlacionada com os recursos imateriais presentes, que constituem o essencial do meio inovador, enquanto ativo econômico intangível ${ }^{2}$.

Podemos definir Meio Inovador como:

um conjunto territorializado dotado de uma forte densidade de fluxos de transações multilaterais (redes de contatos mais ou menos institucionalizadas), de uma diversificação de competências e experiências profissionais e de uma rede de instituições de forte componente informacional, criativa e de inovação (BECATTINI, 1992, citado por DOMINGUES, 1996: 40).

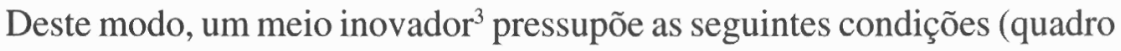
síntese):

\section{CARACTERÍSTICAS ESSENCIAIS DO MEIO INOVADOR}

\begin{tabular}{|c|}
\hline Coexistência de competências profissionais múltiplas \\
\hline Aglomeração da Oferta e da Procura \\
\hline Facilidade de Acesso ao Conhecimento \\
\hline Concentração de emprego qualificado \\
\hline Proximidade de estruturas mediadoras da informação e inovação \\
\hline
\end{tabular}

Fonte: DOMINGUES, 1996

${ }^{2}$ Sobre a importância dos Meios Inovadores num processo de Desenvolvimento Local ver Reis, 1992: 40-41.

${ }^{3}$ Sobre o conceito de Meio Inovador ver também Julião, 2001: 59. 
A leitura do quadro-síntese permite inferir que :

C'est dans la mesure où le milieux innovateur est capable, notamment au travers de la logique d'interaction et de la dynamique d'apprentissage, d'assurer la création de nouvelles ressources et la transformation du système de production qu'on peut mettre clairement en évidence son rôle dans l'évolution des systèmes territoriaux de production ${ }^{4}$ (MAILLAT, 1996: 24).

No sentido da corrente de análise, os recursos humanos podem ser entendidos numa dupla asserção: por um lado, correspondem à base essencial do meio inovador, traduzida no conceito, já especificado, de capital humano e, por outro lado, envolve a "idéia de que o empresário, enquanto ator, está no coração do processo de desenvolvimento econômicos" (POLĖSE, 1998: 220).

Conforme refere-se Becattini:

a especialização do trabalhador - que pode ser característica da empresa ou distrito - faz parte desse bem público designado (na acepção Marshalliana) de "atmosfera industrial" e, por outro lado, o empresário segue de muito perto os acontecimentos que intervêm no mercado dos seus produtos e procura constantemente completar o seu próprio conhecimento do distrito enquanto entidade sócio-cultural» (BECATTINI, 1994: 23).

A procura da inovação por parte da classe empresarial e a formação contínua da mão-de-obra representam, deste modo, um dos vetores primordiais característicos do meio inovador, pelo que:

on peut considérer que lui (le milieu innovateur) joue un peu le rôle de cerveau du système territorial de production en ce sens qu'il constitue une agrégation des facultés cognitives des acteurs du milieu. Une de ces facultés cognitives est la capacité de développer de manière autonome un savoir-faire qui permette la spécialisation du milieu (MAILLAT, 1996: 24).

\footnotetext{
${ }^{4} \mathrm{O}$ conceito de sistema territorial de produção está intimamente ligado à noção, já estudada no presente trabalho, de distrito industrial : « en effet, la notion de district industriel répresente l'un des courants majeurs à partir desquels s'est efectuée la réflexion relative aux relations entre dynamiques industrielles et dynamiques du territoire» (MAILLAT, 1996: 20).

${ }^{5}$ A importância do empresário como fator crucial da dinâmica econômica das regiões ou lugares é «atribuída ao economista alemão Joseph Schumpeter, que defendeu a promoção do espírito de empresa enquanto elemento chave do desenvolvimento da capacidade produtiva» (cf. POLÈSE, 1998: 220).
} 


\section{Caso de estudo - a região do ABCD Paulista}

A região do $\mathrm{ABCD}$, localizada na periferia sul do município de São Paulo, compreende os municípios de Santo $\underline{A}$ dré, São Bernardo do Campo, São Caetano do Sul e Diadema, por vezes referindo-se um "ABCD alargado" aos municípios de Mauá, Ribeirão Pires e Rio Grande da Serra.

Enquanto enquadramento espacial da nossa análise apresentamos, de forma sintética, algumas características do tecido transformador do Estado de São Paulo, com o objetivo de destacar algumas diferenças setoriais-organizacionais-espaciais da indústria neste território:

1) Por um lado, na «(...) estrutura da indústria paulista: os setores de maior geração de valor não têm a mesma participação na ocupação, o que provoca um descompasso entre emprego e geração de riqueza.» (ver quadro I)

2) Outro aspecto reside no «(...) porte das empresas: [uma vez que] há um grande distanciamento dos padrões tecnológico, de gestão dos recursos humanos, de inserção no mercado externo, desempenho inovador e participação do capital estrangeiro entre as empresas pequenas e médias e as grandes.»

3) Em termos espaciais, "o adensamento da atividade industrial na Região Metropolitana de São Paulo e na região localizada no seu entorno (...) faz. com que este espaço detenha $90 \%$ do valor adicionado da atividade industrial. [Porém] este espaço não é homogêneo, já que a estrutura de cada região possui especificidades, como é o caso (...) do município de São Paulo, com uma enorme concentração da indústria editorial e do vestuário; da indústria automobilística na região do $A B C$; da automobilística, química, têxtil e alimentícia em Campinas (...) e da química e metalúrgica em Santos. No interior do Estado, a preponderância é da agroindústria, importante para todas as regiões que compõem este espaço (...)» (FÓRUM SÃO PAULO SÉC. XXI, 1999a: 43) 
QUADRO 1. NÚMERO DE UNIDADES, PESSOAL OCUPADO E VALOR ACRESCENTADO DAS EMPRESAS TRANSFORMADORAS IMPLANTADAS ENTRE 1990-96 NO ESTADO DE SÃO PAULO, POR SETOR DE ATIVIDADE

\begin{tabular}{|c|c|c|c|}
\hline & $\begin{array}{l}\mathrm{N} .{ }^{\circ} \text { de } \\
\text { Unidades } \\
(\%)\end{array}$ & $\begin{array}{l}\text { Valor } \\
\text { Acrescent. } \\
(\%)\end{array}$ & $\begin{array}{l}\text { Pessoal } \\
\text { Ocupado } \\
(\%)\end{array}$ \\
\hline Indústria Extrativa & 1,3 & 0,5 & 0,6 \\
\hline Alimentos e Bebidas & 9,9 & 6,8 & 10,2 \\
\hline Têxtil & 5,1 & 4,7 & 6,2 \\
\hline Vestuário e Acessórios & 19,0 & 6,3 & 12,5 \\
\hline Couro e Calçados & 4,0 & 1,8 & 4,7 \\
\hline Papel e Celulose & 2,1 & 3,7 & 2,8 \\
\hline $\begin{array}{l}\text { Edição, Impres., } \\
\text { Gravaç. }\end{array}$ & 6,0 & 10,0 & 5,5 \\
\hline Refino de Petr. e Álcool & 0,1 & 0,4 & 0,3 \\
\hline Produtos Químicos & 4,0 & 11,9 & 5,5 \\
\hline Borracha e Plástico & 6,1 & 9,3 & 7,8 \\
\hline Minerais Não-Metálicos & 5,3 & 3,4 & 4,8 \\
\hline Metalurgia Básica & 2,5 & 2,5 & 2,8 \\
\hline Produtos de Metal & 9,8 & 7,9 & 8,2 \\
\hline $\begin{array}{l}\text { Máquinas e } \\
\text { Equipamentos }\end{array}$ & 5,9 & 13,4 & 8,3 \\
\hline $\begin{array}{l}\text { Máquinas de Escritório } \\
\text { e Equipamentos de } \\
\text { Informática }\end{array}$ & 0,3 & 1,3 & 0,7 \\
\hline Materiais Elétricos & 2,1 & 3,7 & 3,5 \\
\hline $\begin{array}{l}\text { Mat. Eletrônico e de } \\
\text { Comunicações }\end{array}$ & 1,1 & 1,5 & 1,5 \\
\hline $\begin{array}{l}\text { Equip. Ópticos, } \\
\text { Médicos, de Automação } \\
\text { e Precisão }\end{array}$ & 1,2 & 0,8 & 0,9 \\
\hline Automobilística & 2,4 & 5,7 & 4,5 \\
\hline $\begin{array}{l}\text { Outros Equipamentos } \\
\text { de Transporte }\end{array}$ & 0,4 & 0,5 & 0,6 \\
\hline Outras & 11,4 & 3,9 & 8,1 \\
\hline TOTAL & 100 & 100 & 100 \\
\hline
\end{tabular}

Fonte: Fundação SEADE, in FÓRUM SÃO PAULO SÉC. XXI, 1999a: 40 
No caso concreto do $\mathrm{ABCD}$ paulista e conforme se mencionou em subcapítulo anterior, «foi a implementação do Plano de Metas do governo Juscelino Kubitschek, na segunda metade dos anos cinquenta, que deu à região o perfil de cinturão industrial da Grande São Paulo» (LEITE, 2000:88). Assim, o ABCD paulista irá configurar-se como uma das áreas mais dinâmicas do território brasileiro, sobretudo no domínio das atividades de transformação.

A concentração da atividade industrial na Região Metropolitana de São Paulo (RMSP) constitui um processo resultante de uma série de vantagens que passamos a mencionar:

a) Existência de um mercado urbano mais evoluído, correspondente à Cidade e aos espaços periféricos de São Paulo;

b) Presença de uma rede de comunicações com o exterior mais desenvolvida, de que é o exemplo o Porto de Santos;

c) Abundância de terreno disponível para implantação de estabelecimentos empresariais

d) Perfil de mão-de-obra com alguma qualificação e com baixos custos de reprodução.

Em consequiência deste conjunto de vantagens, «instalou-se na região o parque industrial automotivo, constituído pelas montadoras de autoveículos e suas fornecedoras de autopeças» (LEITE, 2000:88). Outro setor com «grande expressão no $\mathrm{ABCD}$ corresponde à indústria química, que gera mais de $15 \%$ do valor adicionado e $10 \%$ dos empregos na região.» (FÓRUM SÃO PAULO SÉC. XXI, 1999a: 23)

Face ao que antecede, é possível afirmar que a reconfiguração espacial da economia brasileira, ocorrida entre as décadas de cinqüenta e setenta, privilegiou um conjunto de espaços bem delimitados no território correspondentes, no caso em estudo, às áreas periféricas da Cidade de São Paulo. Em consequência deste padrão locacional de atividades, o estado de São Paulo «representa, em 1980 aproximadamente $40 \%$ do produto nacional e abriga dos sectores mais modernos da economia do país» (cf. FÓRUM SÃO PAULO SÉC. XXI, 1999b: 3).

No período que decorre até ao final dos anos setenta, e num contexto de forte crescimento econômico, «o $\mathrm{ABC}$ tornou-se o coração do milagre brasileiro, tendo como carro-chefe desse crescimento a indústria automobilística instalada na região que era responsável pela quase totalidade da produção nacional de autoveículos.» (LEITE, 2000:89)

Neste sentido, podemos considerar que a estruturação do ABCD paulista corresponde, pelo menos parcialmente, e tendo em consideração os contornos econômicos e geográficos que assumiu no seu início e posterior desenvolvimentọ,

${ }^{6}$ Atualmente fala-se muito de "Deseconomias de Escala" no ABCD, não tanto pela falta de terrenos livres em si, mas mais por questões relacionadas com o congestionamento rodoviário e a poluição. 
um "distrito industrial" com a forte tendência de localização de diversas atividades que têm na fabricação automobilística o seu "setor leader".

No entanto, esta linha de raciocínio não deve ser entendida como conclusão absoluta, não sujeita a debate e reflexão. Assim, o ABCD paulista poderá, também, ser considerado um pólo motor de crescimento próximo de um conceito de inspiração keynesiana. Neste sentido, a estruturação do ABCD corresponderia a uma área geográfica palco de grandes investimentos industriais, que despoletariam* fenômenos de arrastamento intersetorial na malha produtiva da região. Nesta perspectiva, o $\mathrm{ABCD}$ paulista constituiria um elemento-chave de uma estratégia funcionalista da promoção do crescimento, com uma aposta bem determinada em certos setores produtivos e áreas geográficas ${ }^{7}$.

Na sua gênese, a formação do ABCD paulista beneficiou-se de vantagens territoriais compreendidas num modelo de organização de produção do tipo fordista, como «mão-de-obra abundante e barata, grandes volumes de recursos naturais e economias de escala» (FÓRUM SÃO PAULO SÉC. XXI, 1999b:10). Deste modo, o poder atrativo desta região motivou a procura de espaços disponíveis para investimentos industriais. Em conseqüência, assistiram-se a alterações profundas nos padrões de uso do solo nos municípios envolvidos, com as parcelas de território afetadas quer a estabelecimentos de transformação, quer a habitação a aumentar de modo muito significativo.

A consolidação da nova estrutura territorial teve, no curto prazo, um conjunto de conseqüências positivas para a economia paulista, como a melhoria dos rendimentos e a modernização da atividade econômica. No entanto, no longo prazo, este modelo de desenvolvimento «será responsável pelo aparecimento de uma série de problemas ou desvantagens económicas (deseconomias de aglomeração) tais como: trânsito caótico, enchentes na época de chuvas, altos custos do porto de Santos, escassez e alto preço da água industrial, poluição ambiental, terrenos supervalorizados» (LEITE, 2000: 89).

Assim, podemos detectar a presença de alguns elementos fragilizadores desta estrutura industrial e que contribuem para a incerteza que, nos dias de hoje, existe quanto às tendências de especialização do $\mathrm{ABCD}$ paulista:

a) Em primeiro lugar, é importante citar o próprio quadro internacional em que as mudanças estão a operar ${ }^{8}$, isto é, nas décadas mais recentes, foi possível assistir-se à alteração da «estrutura da paisagem econômica, com a competitividade variável das atividades, nas diferentes regiões, a resultar em

\footnotetext{
" "desencadeariam" (Nota da Revisão).

${ }^{7} \mathrm{O} \mathrm{ABCD}$ corresponderia, deste modo, a uma área geográfica crucial para a estruturação de um núcleo base promotor do crescimento sustentado do Brasil.

${ }^{8}$ De facto, «nos últimos anos, com a consolidação do processo de abertura económica e a maior penetração de capitais estrangeiros na economia nacional, alguns segmentos passam a sofrer acirrada concorrência de produtos importados, o que levou a retrações na produção fiscal (...) [e] na estrutura produtiva paulista.» (FÓRUM SÃO PAULO SÉC. XXI, 1999a: 5)
} 
taxas de crescimento regional diferenciadas e num aumento das desigualdades espaciais» (BENKO, 1996:126). Deste modo, embora o estado de São Paulo mantenha «diante das demais regiões brasileiras vantagens assinaláveis, como: um parque produtivo já instalado; um mercado de trabalho com mão-de-obra qualificada; infra-estruturas modernas, nomeadamente rodoviárias; concentração de universidades e centros de Investigação \& Desenvolvimento; além uma rede de apoio à produção desenvolvida e consolidada.» (FÓRUM SÃO PAULO SÉC. XXI, 1999b:8), a repartição do investimento estadual com as restantes regiões administrativas do Estado de São Paulo parece estar prejudicando o $\mathrm{ABCD}^{9}$.

b) Por outro lado, as "deseconomias de aglomeração", associadas aos incentivos fiscais oferecidos por outros municípios paulistas e brasileiros e à dificuldade crescente que os sindicatos têm vindo a colocar às empresas locais, "incentivam" a deslocalização de um número crescente de indústrias do ABCD (cf. LEITE, 2000: 89-90);

c) Situação que se interliga com a lógica de decisão das principais empresas integradas no setor-chave da indústria regional. As empresas do setor automóvel, são caracterizadas pelo seu capital transnacional, onde o quadro de decisões produtivas e locacionais são tomadas em função de uma leitura à escala continental e mundial. Deste modo, a região de São Paulo pode não representar indefinidamente a melhor localização para este tipo de estabelecimentos. De fato, tem-se vindo a verificar que as novas empresas de grandes dimensões, instaladas de raiz ${ }^{10}$, procuram localizar-se no interior do estado de São Paulo ou mesmo em outros estados adjacentes, em oposição às PME's que optam por localizar-se no Estado de São Paulo, principalmente na RMSP (cf. FÓRUM SÃO PAULO SÉC. XXI, 1999a: 39);

Concluindo, a "nova" geografia econômica do estado de São Paulo parece caracterizar-se pela "interiorização" de determinados investimentos, em desfavor das áreas centrais tradicionais como é o caso do ABCD. Neste pressuposto:

\section{(...) o novo fluxo de investimentos anunciados para o Estado volta-se} para o interior, e dá continuidade à interiorização do desenvolvimento iniciada em meados dos anos 70. A tendência é homogeneizar as vantagens de localização entre a região metropolitana e parte do interior de São Paulo ${ }^{11}$. Assim, pode-se dizer que os novos investimentos tendem

\footnotetext{
${ }^{9}$ Nos dias de hoje, utiliza-se a expressão "O custo ABC" para designar as externalidades negativas que motivam uma retração do investimento industrial nesta área. (LEITE, 2000: 89-90)

${ }^{10}$ Por vezes referidos como Greenfield Investments.

${ }^{11}$ A localização das novas empresas nas «(...) regiões administrativas situadas no entorno da RMSP (...) acabaram criando uma extensa região econômica ou uma grande "metrópole expandida." " (cf. FÓRUM SÃO PAULO SÉC. XXI, 1999a: 10-11)
} 
a assumir a forma desconcentrada. Graças às suas condições estruturais (...) o interior tem atraido novos investimentos. Também pesam na decisão as deseconomias de aglomeração existentes na metrópole e ainda não presentes no interior. (FÓRUM SÃO PAULO SÉC. XXI, 1999b: 8)

\section{Algumas perspectivas para o futuro}

$\mathrm{O}$ processo de reestruturação do $\mathrm{ABCD}$ que se encontra em curso, caracterizado, como vimos anteriormente, pela perda de importância em determinados sectores industriais que "migram" para o interior do estado de São Paulo em busca de melhores condições de localização/competitividade, deve ser equacionado em função de questões de natureza teórica ligadas, entre outros aspectos, à problemática dos "meios inovadores". Deste modo, podemos considerar que as condições de competitividade desta área se encontram em mutação mais ou menos acelerada, sendo expectável a ocorrência de processos de reestruturação produtiva que conduzam a novos perfis de especialização. Julgamos que não será credível a hipótese de desaparecimento da atividade industrial uma vez que não se deve subestimar «a importância dos fatores não-econômicos - muito em particular da história econômica - como determinantes da localização e especialização econômica» (SALVADOR, 1999 :141)

No sentido "marshalliano" do termo, o distrito industrial deverá possuir uma determinada "atmosfera empresarial", potenciadora de ganhos de produtividade devido às forças da concorrência que estimulam a novidade e a competição acrescida entre empresas. De um modo geral, as unidades empresariais constituintes de um distrito apresentam elevado grau de relacionamento, derivado da consolidação de um conjunto de ligações caracterizadas pela concorrência e, em alguns casos, pela cooperação. Neste sentido, o ABCD, pelo grau tradicional de especialização que apresenta em determinado setor - mais concretamente a produção automobilística - aproxima-se de algumas condições definidas pela teoria e que permitem classificar determinada parcela de território como um "distrito industrial" ou mega-cluster.

No entanto, e alguns estudos nos anos noventa apontam neste sentido, a noção de distrito industrial tem vindo a ser enriquecida através da sua associação ao conceito de cluster, aqui entendido como um conjunto de empresas e outras instituições que, partilhando de um mesmo espaço regional, estabelecem um grau de interligação muito elevado que possibilita o crescimento sustentado da produtividade e o aparecimento contínuo de inovações quer de produtos, quer de

\footnotetext{
12 Ver PORTER (1990)
} 
processos ou formas de gestão. ${ }^{12}$

Face ao que antecede, julgamos mais adequado refletir sobre São Paulo/ $\mathrm{ABCD}$, nomeadamente no que concerne às previsíveis transformações que, necessariamente, terão lugar nos próximos cinco/dez anos, à luz dos conceitos téoricos de "Distrito Industrial/Cluster" e "Meio Inovador".

Acresce, ainda, ao panorama anteriormente dèscrito, que não devemos esquecer, no contexto desta análise, a ligação entre os paradigmas da Nova Geografia Econômica e a Nova Teoria do Crescimento ou Teoria do Crescimento Endógeno. Assim, reserva-se ao Fator Conhecimento um papel crucial na explicação do crescimento econômico e da produtividade, devido ao caráter potencialmente infinito da aquisição de novas técnicas e modos de fazer e gerir. Aceita-se, enquanto pressuposto de enfoque teórico, que o Conhecimento permite gerar constantemente inovações e que, no limite, este processo não conhece um esgotamento ${ }^{13}$.

Nesta linha de raciocínio, os "Distritos Industriais/Clusters" promovem e facilitam a difusão do conhecimento técnico e científico inerente a determinado setor produtivo, em função das relações de proximidade que asseguram. A localização contígua das unidades empresariais permite, por um lado, reforçar a competição e, deste modo, induzir a integração de novidades e, por outro lado, promove a cooperação inter-empresarial, quando tal se justifica em função da dimensão ou da natureza do projeto.

Encontramos aqui o papel da concentração geográfica, enquanto fator que induz o crescimento econômico. As empresas se beneficiam largamente das relações de proximidade uma vez que, entre outros aspectos, a circulação/disponibilidade da informação, em qualidade e em tempo útil de análise, constitui um dos ganhos mais importantes que decorrem deste padrão geográfico de repartição das atividades e os contatos entre fornecedores e vendedores são, igualmente, facilitados.

A Grande São Paulo encontra-se, deste modo, perante a urgência de encontrar um perfil de segmentação produtiva que seja adequado ao tipo de tradição industrial (à sua "história empresarial") que a caracteriza, às habilitações técnicas da sua mão-de-obra e ao seu enquadramento geográfico e econômico face ao todo regional envolvente.

\footnotetext{
${ }^{13}$ Enquanto referência importante a este nível, podemos mencionar que, no seu todo, o tecido de transformação do Estado de São Paulo, apresenta algumas fragilidades dada a «(...) pequena participação das divisões industriais tidas como fundamentais no novo paradigma tecnológico, chamadas de "intensivas em conhecimento" (...), que, somadas, representam [apenas] 7\% do pessoal ocupado e $9 \%$ do valor adicionado da indústria paulista. Essas divisões, que são estratégicas para a inserção em um novo paradigma tecnológico, têm pequena relevância econômica.» (FÓRUM SÃO PAULO SÉC. XXI, 1999a: 8)
} 
Por outro lado, devemos relembrar que, para perfilar um "Meio Inovador" o $\mathrm{ABCD}$ deverá reunir um conjunto de condições que, a seguir, se enumeram de forma sintética:

a) Diversificação das competências da mão-de-obra;

b) Concentração de compradores e fornecedores, especializados e exigentes;

c) Circulação e acesso ao conhecimento facilitados;

d) Qualificação do emprego;

e) Presença de instituições capazes de assegurar o fornecimento da informação e das novidades relativas aos segmentos produtivos presentes no espaço em causa.

Os dados disponíveis mais recentes sobre qualificações da mão-de-obra sugerem que, não obstante o posicionamento favorável desta área face aos valores médios nacionais, ainda existe um longo caminho a percorrer no sentido de o $\mathrm{ABCD}$ poder afirmar-se, no contexto do estado de São Paulo, como um "Meio Inovador", nas condições em que este é definido pela teoria (ver quadro XIII). De fato, os ganhos sustentados de produtividade no interior do ABCD dependerão, em margem considerável, da capacidade de inovar, quer no domínio do produto, quer no que respeita a formas de gestão. ${ }^{14}$

QUADRO II - NÍVEL DE INSTRUÇÃO DA POPULAÇÃO EMPREGADA
\begin{tabular}{|l|c|}
\hline \multicolumn{1}{|c|}{ NA RMel de Instrução } & RMSP (\%) \\
\hline Fundamental Incompleto $^{(1)}$ & 43,0 \\
\hline Fundamental Completo $^{(2)}$ & 19,5 \\
\hline Pelo Menos Médio Completo & 37,5 \\
\hline Total & 100 \\
\hline a) Inclusive os analfabetos \\
b) Inclusive Médio Incompleto \\
Fonte: SEP e PED, in FÓRUM SÃO PAULO SÉC. XXI, 1999d: 18
\end{tabular}

O tipo de alterações acima mencionado poderá ser conseguido através de melhorias contínuas na formação dos trabalhadores e mediante um esforço considerável nas áreas da gestão e organização da produção. Aliás, é conveniente recordar que um dos traços mais importantes dos modelos de acumulação alternativos ao fordismo corresponde, precisamente, às mutações estruturais na

\footnotetext{
${ }^{14}$ «Comparado ao perfil dos países desenvolvidos, ainda persiste, no Estado de São Paulo, um contingente expressivo de trabalhadores com baixa escolaridade.» (cf. FÓRUM SÃO PAULO SÉC. XXI, 1999d: 18)
} 
esfera da organização e gestão empresariais. A designada "especialização flexível", por exemplo, baseia parte da sua construção conceitual numa perspectiva de introdução de inovações, que promovam a melhor e mais racional gestão das empresas (nomeadamente das bem conhecidas Pequenas e Médias Empresas PME's) (ver neste sentido BOYER, 1994).

Podemos ainda acrescentar, e tendo em consideração a lógica territorial do espaço onde se integra $\mathrm{o} \mathrm{ABCD}$, que a proximidade geográfica face à Cidade de São Paulo, pelo que pode representar de acesso a informação e a estruturas produtoras de conhecimento (como as Universidades) e pela contigüidade espacial que implica relativamente ao principal mercado consumidor do Brasil, constitui um valor suplementar para esta parcela da RMSP. Deste modo, encontram-se reunidas algumas pré-condições para a afirmação do ABCD como um "Meio Inovador", localizado no "coração" do estado de São Paulo.

Este processo de reestruturação (pelo acréscimo de riqueza que deverá induzir) poderá representar um importante mecanismo de suporte a um conjunto de transformações de índole social, nomeadamente nas áreas habitacional e urbanística, que promovam uma melhoria efetiva das condições de vida na Região Metropolitana de São Paulo e, por conseqüência, permitam reduzir algumas das atuais manifestações dos problemas associados à pobreza.

Resumo: Este artigo propõe tratar dos conceitos de Distritos Industriais e Clusters. A idéia básica procura analisar em que medida o assim chamado "ABCD Paulista" pode ser considerado um Distrito Industrial ou um Cluster. Tentamos analisar os principais padrões organizacionais da atividade industrial nos quatro municípios que formam o $\mathrm{ABCD}$ Paulista. Na mesma linha de raciocínio discutem-se possíveis mudanças futuras, incluindo impactos dessas mudanças na política fiscal.

Palavras-Chave: ABCD Paulista - Distritos Industriais - Clusters

THE CHANGING PATTERN OF THE LOCATION OF ECONOMIC ACTIVITIES IN THE STATE OF SÃO PAULO: THE CASE OF "ABCD PAULISTA"

Abstract: The present article deals with the concepts of Industrial Districts and Clusters. The main idea behind our analysis is to study in which measure the so called "ABCD Paulista" can be considered as an Industrial District or a Cluster. We try to analyze the main organizational patterns of the industrial activity in the four municipalities that compound the ABCD Paulista. In the same line of reasoning we discuss several possible changes towards the near future, including the impacts of changes in local taxes.

Keywords: ABCD Paulista - Industrial Districts - Clusters

\section{BIBLIOGRAFIA}

ANDRADE, Thompson Almeida e SERRA, Rodrigo Valente s/d. Desconcentração Industrial no Brasil: 1990/95. In: NEMESIS - Núcleo de Estudos e 
Modelos Espaciais Sistêmicos (Disponível em: www.nemesis.org.br/docs/thomp6.pdf)

BECATTINI, Giacomo. 1992. Le District Industriel: milieu créatif. In : Espaces et Sociétés n. ${ }^{\circ}$ 66/67. Paris : Éditions L'Harmattan, pp. 145-163.

1994 (1992) O Distrito Marshalliano. In : As Regiões Ganhadoras Distritos e Redes: Os Novos Paradigmas da Gèografia Económica, trad. António Gonçalves. Oeiras: Celta Editora, pp. 19-31.

BENKO, Georges. 1996. Economia, Espaço e Globalização. Trad. Antônio de Pádua Donesi. São Paulo: HUCITEC, São Paulo.

BOYER, Robert. 1994 (1992). As Alternativas ao Fordismo. In: As Regiões Ganhadoras -Distritos e Redes: Os Novos Paradigmas da Geografia Económica, trad. António Gonçalves. Oeiras: Celta Editora, pp. 121-142. DOMINGUES, Álvaro. 1996. Política Urbana e Competitividade. Sociedade e Território n. ${ }^{\circ}$ 23, Porto, pp. 31-42.

FÓRUM SÃO PAULO SÉC. XXI. 1999a Indústria. In: Cadernos do Fórum São Paulo Século XXI - 11. (Disponível em http://www.al.sp.gov.br/forum/ cadernos/Industria.pdf)

1999b. Habitação e Desenvolvimento Urbano. In: Cadernos do Fórum São Paulo Século XXI - 5. (Disponível em: http://www.al.sp.gov.br/forum/ cadernos/Habitacao e Desenvolvimento Urbano.pdf) 1999c. Terceiro Setor. In: Cadernos do Fórum São Paulo Século XXI 8. 0(Disponível em: http://www.al.sp.gov.br/forum/cadernos/Terceiro Setor.pdf)

1999d. Trabalho e Emprego. In: Cadernos do Fórum São Paulo Século $X X I$ - 9. Disponível:http://www.al.sp.gov.br/forum/cadernos/Trabalho eEmprego.pdf

KUPFER, David. 1998. Trajectórias de Reestruturação da Indústria Brasileira após a Abertura e a Estabilização. Tese de Doutoramento em Economia, Instituto de Economia da UFRJ, Rio de Janeiro. (Disponível em: http:// www.ie.ufrj.br/gic/pdfs/1998-1 Kupfer.pdf)

LEITE, Márcia de Paula. 2000. Sindicatos e desenvolvimento econômico: A experiência da Câmara Regional do Grande ABC no Brasil. In: De la Graza

Toledo, Enrique (org.) Reestructuración Productiva, Mercado de Trabajo y Sindicatos en América Latina. Buenos Aires: CLACSO, pp. 87-120. (Disponível em: www.clacso.org/wwwclacso/espanol/html/libros/ trabajo2/4.pdf)

MAILLAT, Denis (1996) Milieux innovateurs et dynamiques des systèmes territoriaux de production. Sociedade e Território n. ${ }^{\circ} 23$, Porto, pp. 1930 .

PACHECO, Carlos Américo. 1999. Novos Padrões de Localização Industrial? 
Tendências Recentes dos Indicadores a Produção e do Investimento Industrial. Instituto de Pesquisa Econômica Aplicada, texto para discussão $n{ }^{\circ}$ 633. Brasília: Ministério do Planejamento. (Disponível em: www.ipea.gov.br/pub/td/td 99/td 633.pdf)

PAMPLONA, João Batista (org.) 2000. A atividade econômica nos anos 90 no Grande

ABC - Segunda análise dos resultados da PAEP/ABC: Reestruturação e inovação na indústria. Santo André: Agência de Desenvolvimento Econômico do Grande ABC.

1999. A atividade econômica nos anos 90 no Grande $A B C$ - Primeira análise dos resultados da PAEP/ABC. Santo André: Agência de Desenvolvimento Econômico do Grande ABC.

POLÈSE, Mario. 1998. Economia Urbana e Regional. Coimbra: ADPR.

PONTES, José Pedro e SALVADOR, Regina. 2002. A Nova Geografia Econômica. In: COSTA, José Silva (org.) Compêndio de Economia Regional.. Coimbra: ADPR, pp. 263-281.

PORTER, Michael. 1990. The Competitive Advantage of Nations. Nova York: Free Press..

RODRÍGUEZ-POSE, Andrés; TOMANEY, John e KLINK, J. 2001. Local empowerment through economic restructuring in Brazil: the case of the Greater ABC region. Geoforum, 32 (4) pp. 459-469. (Disponível em: http:/ /personal.lse.ac.uk/RODRIGU1/geoforum.pdf)

RODRÍGUEZ-POSE, Andrés e TOMANEY, John. 1999. Industrial crisis in the centre of the periphery: stabilisation, economic restructuring and policy responses in the São Paulo metropolitan region. Urban Studies, 36, 3, pp. 479-498. (Disponível em: http://personal.lse.ac.uk/RODRIGU1/ urbanstudies 1999.pdf)

RODRÍGUEZ-POSE, Andrés e ARBIX, Glauco. 2001. Strategies of Waste: bidding wars in the Brazilian automobile sector. International Journal of Urban and Regional Research 25, 1, pp. 134-154. (Disponível em: $\underline{\text { http:// }}$ personal.1se.ac.uk/RODRIGU1/ijurr 2001.pdf)

SABOIA, João. 2001. Descentralização industrial no Brasil na década de noventa: um processo dinâmico e diferenciado regionalmente. Nova Economia Revista do Departamento de Ciências Econômicas da UFRJ, Vol. 11, N. ${ }^{\circ}$ 2, Dez. 2001, Rio de Janeiro (Disponível em http:// www.face.ufmg.br/novaeconomia/sumarios/v11n2/SABOIA.pdf)

SALVADOR, Regina. 1999. Geografia e Economia: Um casamento de conveniência. Geolnova n. ${ }^{\circ}$, Centro de Estudos de Geografia e Planeamento Regional, Faculdade de Ciências Sociais e Humanas, pp. 133-145. 
SANTOS, Domingos. 2002. Teorias de inovação de base territorial - contributos teóricos. In: COSTA, José Silva (org.) Compêndio de Economia Regional, ADPR, Coimbra, pp. 285-313.

SCOTT, Allen. 1994 (1992) A Economia Metropolitana. In: As Regiões Ganhadoras Distritos e Redes: Os Novos Paradigmas da Geografia Económica, trad. António Gonçalves. Oeiras: Celta Editora, pp. 63-73.

STORPER, Michael e HARRISON, Bennett. 1994 (1992) Flexibilidade, Hierarquia e Desenvolvimento Regional. In: As Regiões Ganhadoras -Distritos e Redes: Os Novos Paradigmas da Geografia Económica, trad. António Gonçalves. Oeiras: Celta Editora, pp. 171-187.

TAVARES, Hermes Magalhães. 2000. Reestruturação econômica e as novas funções do espaços metropolitanos. Grupo de Trabajo sobre Desarrollo Urbano de CLACSO, 30 e 31 de Março Rio de Janeiro. (Disponível em: http://168.96.200.17/ar/libros/urbano/tavares.pdf)

TOLEDO, Enrique (org.) Reestructuración productiva, Mercado de Trabajo y Sindicatos en América Latina. Buenos Aires: CLACSO, pp. 87-120. (Disponível em: www.clacso.org/wwwclacso/espanol/html/libros/ trabajo2/4.pdf

WORLD BANK. 2001. City Assistance Strategy Programme (CASP) with the Greater ABC Region (Metropolitan Region of São Paulo, Brazil). (Disponível em: http://www.worldbank.org/urban/led/iw2001/ santo andre.pdf)

YÁZIGI, Eduardo Abdo. 2000. O Mundo das Calçadas. São Paulo: Humanitas FFLCH/USP, Imprensa Oficial do Estado. 